CLINICAL PRACTICE

\title{
Warfarin in non-valvular atrial fibrillation
}

\author{
A J Dalby, FCP (SA), FACC, FESC; P Wessels, MB ChB, MMed (Haem), Cert Clin Haem, \\ L H Opie, MD, DPhil, FRCP, FCP (SA, Hon), FACC, FESC
}

Dr Anthony Dalby is a cardiologist in private practice at the Milpark Hospital, Johannesburg, South Africa. Dr Pieter Wessels is a haematologist at Ampath Laboratories, Pretoria, South Africa. Professor Lionel Opie is Director Emeritus at the Hatter Institute for Cardiovascular Research in Africa, Faculty of Health Sciences, University of Cape Town, South Africa

Correspondingauthor: A J Dalby (ajd@hot.co.za)

The development of novel oral anticoagulants that are effective alternatives to warfarin in non-valvular atrial fibrillation (AF) is a welcome advance. However, a variety of unresolved problems with their use, and not least with their cost, make it important to re-evaluate the use of warfarin as it will likely remain the anticoagulant of choice in South African patients with non-valvular AF for the foreseeable future. In this article, we review the correct clinical use of warfarin. Guidance is provided on commencing warfarin treatment, maintenance dosing, the recommended steps when temporary withdrawal of treatment is necessary, the management of bleeding, and the use of warfarin in chronic kidney disease. Techniques for changing from warfarin to one of the new oral anticoagulants and vice versa are included.

S Afr Med J 2013;103(12):901-904. DOI:10.7196/SAMJ.7172

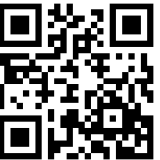

Although the benefits of the novel oral anticoagulants (dabigatran, rivaroxaban, and apixaban) may surpass warfarin in non-valvular atrial fibrillation (AF), their high cost makes them unaffordable to most South Africans. Therefore, it remains imperative that optimal management of warfarin anticoagulation is provided to these patients.

Warfarin's superiority over antiplatelet therapies in preventing stroke and systemic embolism in patients with non-valvular AF has been firmly established for more than a decade. Warfarin reduces stroke risk by $68 \% \cdot{ }^{[1]}$ Optimal results depend on maintenance of the international normalised ratio (INR) within the therapeutic range (INR 2 - 3). Lower values are associated with an excess of thrombo-embolic events and higher values with increased bleeding. ${ }^{[2,3]}$ Notably, in clinical trials and in practice the ideal therapeutic effect is obtained in less than half of all patients, in the remainder, almost $40 \%$ are in a sub-therapeutic range while approximately $20 \%$ are supratherapeutic. ${ }^{[4,5]}$

Anticoagulation for non-valvular AF balances the risk of thromboembolism against the risk of haemorrhage. The $\mathrm{CHA}_{2} \mathrm{DS}_{2}-\mathrm{VASc}$ score ${ }^{\left[{ }^{[6]}\right.}$ most accurately predicts the risk of thrombo-embolism and stroke (Table 1). Anticoagulation is recommended for a $\mathrm{CHA}_{2} \mathrm{DS}_{2}$-VASc score of $>1$; essentially this includes all non-valvular AF patients with the exception of those $<65$ years of age with lone AF. The risk of bleeding is predicted from the HAS-BLED score (Table 2) ${ }^{[7]}$ which should not be used to deny anticoagulation to anyone, other than those at low risk of thrombo-embolism. ${ }^{\left[{ }^{[6]}\right.}$

\section{Problems of warfarin use}

Warfarin has a narrow therapeutic window, slow onset and offset of action, and an unpredictable response demanding a frequent monitoring of the INR, dose adjustment and awareness of interactions with food and with other drugs. These issues require careful explanation to patients to ensure their compliance. The clinician must manage the logistics of patient education, ongoing support and regular drug administration. Physicians' resistance to using warfarin effectively has been ascribed to the fear of causing intracranial haemorrhage. ${ }^{[8]}$ However, in a large cohort study the risk of intracranial bleeding on warfarin exceeded the risk of ischaemic stroke off warfarin in only $0.4 \%$ of patients. Thus, almost all patients with $\mathrm{AF}$ have more to gain than to lose from anticoagulation with warfarin. ${ }^{[9]}$

\section{Initiating warfarin therapy}

A baseline prothrombin time should be obtained in all patients. A personal or family history of bleeding merits investigation before starting treatment. Warfarin therapy should be commenced without a loading dose, usually at $5 \mathrm{mg}$ daily. A lower starting dose is appropriate in the aged, the frail or malnourished, and those with a low body weight, congestive heart failure or impaired kidney function or with concomitant medication increasing warfarin sensitivity. ${ }^{[10]}$ The starting dose may be estimated using an algorithm based upon the clinical and demographic patient characteristics including genetic information if available (http://www.warfarindosing.org/Source/Home.aspx).

It takes several days to fully establish warfarin's anticoagulant effect. When anticoagulation is required immediately, full anticoagulant doses of unfractionated heparin (UH) or low molecular weight heparin (LMWH) should be given concomitantly until 4 days after a therapeutic INR is reached. Two consecutive INR values should be in the therapeutic range during the overlap.

Once the therapeutic range (INR 2 - 3) is reached, INR testing should be repeated at least twice at 2 - 4-day intervals to ensure the stability of anticoagulation.

\section{Maintenance of a therapeutic INR}

Arbitrary warfarin dose adjustment frequently overcorrects the INR. Not adjusting the dose when the INR is in range and only making small (10 - 15\%) adjustments for the vast majority of those out of range improves the time in therapeutic range and clinical outcomes. ${ }^{[1]}$ Changes in dose are best guided by an algorithm promoting minor changes in the total weekly warfarin dose and reassessing the effect of the change within a week (Table 3).

Minor bleeding is a common occurrence in anticoagulated patients and should not readily lead to dose adjustment or discontinuation of therapy. ${ }^{[12]}$

When the INR deviates above 5 in patients who are not bleeding, 1 - 2 doses of warfarin should be withheld and the maintenance dose adjusted downwards. Should the INR rise above $8,1-5 \mathrm{mg}$ of 
Table 1. The $\mathrm{CHA}_{2} \mathrm{DS}_{2}$-VASc score: A point-based, risk-factor approach to the assessment of stroke risk ${ }^{[6]}$

\begin{tabular}{lll}
\hline Letter & Risk factor & Score \\
\hline $\mathrm{C}$ & Congestive heart failure/LV dysfunction & 1 \\
$\mathrm{H}$ & Hypertension & 1 \\
$\mathrm{~A}_{2}$ & Age $\geq 75$ years & 2 \\
$\mathrm{D}$ & Diabetes mellitus & 1 \\
$\mathrm{~S}_{2}$ & Stroke/TIA/thrombo-embolism & 2 \\
$\mathrm{~V}$ & Vascular disease & 1 \\
$\mathrm{~A}$ & Age 65 - 74 years & 1 \\
$\mathrm{Sc}$ & Sex category (i.e. female) & 1 \\
Max. score & & 9 \\
LV $=$ left ventricular; TIA = transient ischaemic attack. &
\end{tabular}

Table 2. The HAS-BLED score: The clinical characteristics contributing to the risk of bleeding ${ }^{[6]}$

\begin{tabular}{lll}
\hline Letter & Clinical characteristic & Score \\
\hline $\mathrm{H}$ & Hypertension & 1 \\
$\mathrm{~A}$ & Abnormal renal and/or liver function & 1 or $2^{*}$ \\
$\mathrm{~S}$ & Stroke & 1 \\
$\mathrm{~B}$ & Bleeding & 1 \\
$\mathrm{~L}$ & Labile INRs & 1 \\
$\mathrm{E}$ & Elderly (age $>65$ years) & 1 \\
$\mathrm{D}$ & Drugs and/or alcohol & 1 or $2^{*}$ \\
Max. score & & 9 \\
INRs = international normalised ratios. &
\end{tabular}

Table 3. Algorithm for maintenance dosing of warfarin*

\begin{tabular}{|c|c|c|}
\hline $\mathbf{I N R}^{\dagger}$ & Dose adjustment $^{\ddagger}$ & Retest \\
\hline$<1.5$ & Increase by $15 \%$ & 1 week \\
\hline$>1.5-<2$ & Increase by $10 \%$ & 1 week \\
\hline $2-3$ & No change & \\
\hline $3-<4$ & Decrease by $10 \%$ & 1 week \\
\hline $4-<5$ & $\begin{array}{l}\text { Hold dose for one day, then } \\
\text { decrease by } 10 \%\end{array}$ & 3 - 7 days \\
\hline $5-<8$ & $\begin{array}{l}\text { Hold dose until INR is therapeutic, then } \\
\text { decrease by } 15 \%\end{array}$ & 2 days \\
\hline \multicolumn{3}{|c|}{$\begin{array}{l}\text { INR }=\text { international normalised ratio. } \\
{ }^{*} \text { Adapted from van Spall et al. }{ }^{[11]} \\
\text { 'If the INR is }>5 \text { and there is a high risk of bleeding, or if the INR is }>8 \text {, administer } 1-5 \mathrm{mg} \\
\text { vitamin K orally. Patients with an INR }>8 \text { should be assessed clinically for the presence of } \\
\text { bleeding. }\end{array}$} \\
\hline
\end{tabular}

vitamin $\mathrm{K}$ should be given orally and the INR checked $24 \mathrm{~h}$ later to assess whether further vitamin $\mathrm{K}$ is needed. ${ }^{[13]}$

INR testing should occur at least monthly after a stable warfarin dose is achieved.

Self-monitoring and self-management of oral anticoagulation is safe for suitable patients of all ages and reduces thromboembolic events by almost $50 \%{ }^{[14]}$ In South Africa, the cost of home monitoring is similar to the cost of INR testing and dosing by pathology laboratories.

\section{Temporary withdrawal of warfarin in the peri-operative period}

Prolonged withdrawal of warfarin before major surgery is associated with a high risk of systemic embolism if alternative anticoagulation is not provided. However, if the INR is in the therapeutic range warfarin need not be withdrawn for minor surgical procedures (Table 4), or pacemaker or cardiac defibrillator implantation. ${ }^{[15,16]}$

Bridging is required for major surgery, which means the timeous preoperative withdrawal of warfarin while introducing UH or LMWH prior to surgery, and the postoperative reintroduction of anticoagulation.

Based upon the prevailing INR, warfarin should be withdrawn in sufficient time to allow the INR to fall. The patient's usual warfarin dose should be taken into account; the lower the usual dose, the longer it may take. Of patients whose INR is in the therapeutic range, $93 \%$ will typically have an INR of $<1.5$ five days after stopping warfarin. ${ }^{[17]}$ The hiatus in anticoagulation may be bridged with either UH or LMWH. Out-of-hospital self-administration of $1 \mathrm{mg} / \mathrm{kg}$ enoxaparin 12-hourly subcutaneously is more costeffective (instruction on injection technique should be provided). LMWH is usually introduced $36 \mathrm{~h}$ after stopping warfarin. The dose of enoxaparin should be reduced by $25 \%$ in the elderly and those weighing $<60 \mathrm{~kg}$. In severe kidney dysfunction the dose frequency should be reduced to $1 \mathrm{mg} / \mathrm{kg}$ daily to compensate for diminished renal excretion. Dose adjustment according to anti-factor Xa (antiFXa) activity measured $2-3 \mathrm{~h}$ after administration is suggested in patients receiving decreased doses, those with decreased renal function and obese patients (who may need larger doses) ${ }^{[18]}$ An antiFXa therapeutic target value of $0.5-1 \mathrm{IU} / \mathrm{ml}$ is suggested although it has not been validated. ${ }^{[19]} \mathrm{UH}$ or LMWH should be withdrawn during the last $24 \mathrm{~h}$ before surgery.

In patients at high risk of intraoperative bleeding it is safe to operate when the INR is $<1.5 .{ }^{[20]}$

\section{Bridging for elective surgery}

The decision to bridge balances thrombo-embolic risk against the risk of peri-operative haemorrhage. ${ }^{[2]]}$ The input and concurrence of the surgeon is invaluable. Although the incidence of thromboembolism may be similar with bridging or no bridging, bridging may be associated with a higher risk of bleeding. ${ }^{[22]}$ However, generalisation is difficult because the timing of warfarin withdrawal, the type, dose and timing of heparin used to replace warfarin, and the reintroduction of anticoagulation postoperatively varied significantly among studies.

Patients at high and moderate thrombo-embolic risk $\left(\mathrm{CHA}_{2} \mathrm{DS}_{2}-\right.$ VASc score $>4$ ) should receive the shorter-acting anticoagulant in full dose, whereas in those at lower risk a low-dose regimen or no bridging may be sufficient. ${ }^{[23]}$

Anticoagulation is reintroduced as soon as feasible after surgery, using either $\mathrm{UH}$ or $\mathrm{LMWH}$ in combination with warfarin. The UH/LMWH dose used depends upon the residual bleeding risk as determined by the surgeon. It is prudent to begin with lower doses and up-titrate daily according to the observed response. Warfarin is usually recommenced at the dose used preoperatively but may require adjustment if medications interacting with warfarin have been introduced peri-operatively. The INR should be measured daily during this phase. UH/LMWH should be continued until 4 days after a therapeutic INR is reached. Two consecutive INR values should be in the therapeutic range during the overlap.

Table 5 outlines a protocol used for bridging therapy ${ }^{[15]}$ 


\section{Withdrawal for urgent and emergent surgery}

Although there are no specific antidotes for warfarin, rapid and effective reversal of its effect is possible, in contrast to the novel oral anticoagulants for which specific reversing agents are presently

$\begin{aligned} & \text { Table 4. Procedures } \\ & \text { discontinuing warfarin }{ }^{[15]}\end{aligned}$
$\begin{array}{ll}\text { Ophthalmological be performed without } & \text { Cataract surgery } \\ \text { Dental } & \text { Trabeculectomy } \\ & \text { Uncomplicated extraction } \\ & \text { Dental hygiene } \\ & \text { Restorations } \\ & \text { Endodontics } \\ & \text { Prosthetics } \\ & \text { Periodontal therapy } \\ & \text { Chemosurgery for skin cancer (Mohs surgery) } \\ & \text { Simple excisions } \\ \text { Dermatological } & \text { Diagnostic OGD } \\ & \text { Colonoscopy without biopsy } \\ \text { Gastrointestinal } & \text { Diagnostic ERCP } \\ & \text { Biliary stent without sphincterotomy } \\ & \text { EUS without biopsy } \\ & \text { Push enteroscopy }\end{array}$
$\begin{array}{ll}\text { OGD = oesophagogastroduodenoscopy; ERCP = endoscopic retrograde cholangio- } \\ \text { pancreatography; EUS = endoscopic ultrasonography. }\end{array}$

lacking ${ }^{[23]}$ When urgent surgical intervention is indicated, the INR should be measured immediately. As vitamin $\mathrm{K}$ is slow-acting, it will most frequently be necessary to administer both prothrombin complex concentrate (PCC) and vitamin K intravenously to correct the INR to an acceptable level in patients requiring surgery within $12 \mathrm{~h}$. If surgery can be delayed for $>12 \mathrm{~h}$, vitamin $\mathrm{K}$ alone may suffice. ${ }^{[13]}$ In either case the INR should be monitored frequently as it may rise again once the effects of the reversing agents dissipate.

\section{Warfarin interactions}

There are significant risks of drug-drug, drug-food and drug-herb interactions with warfarin. Courses of antibiotics or non-steroidal anti-inflammatories most frequently perturb warfarin's effect. Although a large number of interactions have been described, most report on potentiation of warfarin's effect in a single case. ${ }^{[24]}$ The INR should be monitored frequently when any new drug is introduced in a patient taking warfarin.

\section{Management of bleeding with warfarin}

Anticoagulant-associated bleeding is serious. In patients admitted for vitamin $\mathrm{K}$ antagonist-associated bleeding, the in-hospital mortality rate was $7.6 \%$ and 90 -day mortality was $14 \% ; 15 \%$ of survivors were dependent on help with activities of daily living thereafter. ${ }^{[25]}$ The INR should be checked immediately whenever bleeding occurs. If the INR is within the therapeutic range, warfarin should be continued and the source of bleeding treated on its own merits. Significant bleeding should be treated with $1-3 \mathrm{mg}$ vitamin $\mathrm{K}$ given by an intravenous or oral route. In major bleeding, warfarin can be reversed rapidly by 25 - $50 \mathrm{U} / \mathrm{kg}$ four-factor PCC and $5 \mathrm{mg}$ vitamin $\mathrm{K}$ given intravenously. Fresh frozen plasma produces suboptimal reversal and should be used only when PCC is unavailable. Recombinant factor VIIa is not recommended for emergency reversal. ${ }^{[13]}$

Table 5. Protocol for bridging therapy for elective surgery when the temporary withdrawal of warfarin is required ${ }^{*}$

\begin{tabular}{|c|c|}
\hline Day & Protocol \\
\hline \multicolumn{2}{|l|}{ Before surgery } \\
\hline-7 & Check INR \\
\hline-6 & Stop warfarin if INR is $3-4.5$ or if regular warfarin dose unusually low \\
\hline-5 & Stop warfarin if INR is $2-3$ or if regular warfarin dose unusually high \\
\hline-4 & $\begin{array}{l}\text { Start short-acting anticoagulant (UH/LMWH) } \\
\text { Enoxaparin preferred: } 1 \mathrm{mg} / \mathrm{kg} 12 \text {-hourly. Adjust dose in the elderly, low body weight, frail, impaired kidney function } \\
\text { Measure anti-FXa } 2-3 \mathrm{~h} \text { after administration, especially when dose adjustment is required }\end{array}$ \\
\hline-1 & $\begin{array}{l}\text { Stop short-acting anticoagulant } 24 \mathrm{~h} \text { before surgery } \\
\text { Check INR } \\
\text { If INR }<1.5 \text { (some surgeons prefer }<1.2 \text { ) proceed to surgery }\end{array}$ \\
\hline \multicolumn{2}{|l|}{ Day of surgery } \\
\hline 0 & $\begin{array}{l}\text { No anticoagulant } \\
\text { Use mechanical prophylaxis to prevent DVT }\end{array}$ \\
\hline \multicolumn{2}{|l|}{ After surgery } \\
\hline+1 & $\begin{array}{l}\text { Minor surgery: Commence full-dose LMWH } \\
\text { Major surgery: Commence reduced-dose LMWH } \\
\text { Recommence warfarin in usual dose. Adjust dose if medication has been introduced that could influence warfarin's effect } \\
\text { Order daily INR }\end{array}$ \\
\hline+2 and beyond & $\begin{array}{l}\text { Consider up-titration of LMWH if not on already on full dose } \\
\text { Continue warfarin and LMWH until INR }>2 \text { for } 4 \text { consecutive days }\end{array}$ \\
\hline
\end{tabular}




\section{Warfarin in chronic kidney disease}

Chronic kidney disease (CKD) increases the risk of both stroke and bleeding in non-valvular AF. ${ }^{[2]}$ Because INR in CKD patients is often labile, such patients require lower doses of warfarin and more frequent testing and dose adjustment. ${ }^{[27]}$ While warfarin effectively reduces stroke risk and is safe in moderate stage $3 \mathrm{CKD}$ (creatinine clearance $30-60 \mathrm{ml} / \mathrm{min}$ ), its value is less certain in end-stage renal disease. ${ }^{[28,29]}$

\section{Discontinuing warfarin when commencing treatment with a novel oral anticoagulant}

When changing to one of the novel oral anticoagulants, warfarin should be withdrawn and the INR monitored daily. The novel oral anticoagulant may be commenced once the INR has fallen below 2. However, a survey of dabigatran reported increased rates of both thrombo-embolism and bleeding among previous warfarin users during the early months of the transition. ${ }^{[30]}$

\section{Discontinuing a novel oral anticoagulant when commencing warfarin treatment}

As highlighted by the experience with rivaroxaban, the withdrawal of the novel oral anticoagulants may lead to inadequate anticoagulation and thrombo-embolism. ${ }^{[31]}$ As all the novel oral anticoagulants have a short duration of action, warfarin should be commenced on the day after withdrawal in combination with bridging therapy if the risk of thrombo-embolism is high. The INR should be monitored frequently until the therapeutic range is achieved.

1. Hart RG, Benavente O, McBride R, Pearce LA. Antithrombotic therapy to prevent stroke in patient with atrial fibrillation: A meta-analysis. Ann Intern Med 1999;131(7):492-501. [http://dx.do org/10.7326/0003-4819-131-7-199910050-00003]

2. Shulman S, Beyth RJ, Kearon C, et al. Hemorrhagic complications of anticoagulant and thrombolytic treatment: American College of Chest Physicians Evidence-Based Clinical Practice Guidelines (8th edition). Chest 2008;133(6_Suppl):257S-298S. [http://dx.doi.org/10.1378/chest.08-0674]

3. Rose AJ, Ozonoff A, Grant RW, et al. The epidemiology of sub-therapeutic anticoagulation in the United States. Circ Cardiovasc Qual Outcomes 2009;2:591-597. [http://dx.doi.org/10.1161/ CIRCOUTCOMES.109.862763]

4. Petersen P, Grind M, Adler J; SPORTIF II Investigators. Ximelagatran versus warfarin for stroke prevention in patients with nonvalvular atrial fibrillation. SPORTIF II: A dose-guiding, tolerability, and safety study I Am Coll Cardiol 2003:41(9):1445-1451.

5. Samsa GP, Matcher DB, Goldstein LB, et al. Quality of anticoagulation management among patients with atrial fibrillation. Arch Intern Med 2000;160(7):967-973. [http://dx.doi.org/10.1001/ archinte.160.7.967

6. Camm AJ, Kirchof P, Lip GYH, et al. Guidelines for the management of atrial fibrillation: The task force for the management of atrial fibrillation of the European Society of Cardiology (ESC). Eur Hear J 2010;31(19):2369-2429. [http://dx.doi.org/10.1093/eurheartj/ehq278]

7. Camm AJ, Lip GYH, de Caterina R, et al. 2012 focussed update of the ESC Guidelines for the management of atrial fibrillation: An update of the 2010 ESC Guidelines for the management of atrial fibrillation. Developed with the special contribution of the European Heart Rhythm Association. Eur Heart J 2012;33(21):2719-2747. [http://dx.doi.org/10.1093/eurheartj/ehs253]

8. Gross $\mathrm{CP}$, Vogel EW, Dohnd AJ, et al. Factors influencing physicians' reported use of anticoagulation therapy in nonvalvular atrial fibrillation: A cross-sectional survey. Clin Ther 2003:25(6):1750-1764. [http://dx.doi.org/10.1016/S0149-2918(03)80167-4]
9. Friberg L, Rosenqvist M, Lip GY. Net clinical benefit of warfarin in patients with atrial fibrillation: A report from the Swedish Atrial Fibrillation Cohort Study. Circulation 2012;125(19):2298-2307. [http:// dx.doi.org/10.1161/CIRCULATIONAHA.111.055079]

10. Ansell J, Hirsh J, Hylek E, et al. Pharmacology and management of the Vitamin K antagonists: Ansell J, Hirsh J, Hylek E, et al. Pharmacology and management of the Vitamin $\mathrm{K}$ antagonists:
American College of Chest Physicians evidence-based clinical practice guidelines (8th edition). Chest 2008;133(6 Suppl):160S-198S. [http://dx.doi.org/10.1378/chest.08-0670]

11. van Spall HGC, Wallentin L, Yusuf S, et al. Variation in warfarin dose adjustment practice is responsible for variations in the quality of anticoagulation control between centers and countries: An analysis of patients receiving warfarin in the Randomized Evaluation of Long-term Anticoagulation Therapy (RE-LY) trial. Circulation 2012;126(19):2309-2316. [http://dx.doi.org/10.1161/ CIRCULATIONAHA.112.101808]

12. Heidbuchel H, Verhamme P, Ailings M, et al. European Heart Rhythm Association practical guide on the use of new oral anticoagulants in patients with non-valvular atrial fibrillation. Europace 2013;15(5):625-651. [http://dx.doi.org/10.1093/europace/eut083]

13. Tait CR, Mumford AD, Laffan M. British Committee for Standards in Haematology. Guideline on the management of bleeding in patients on antithrombotic agents. Br J Haematol 2013;160(1):35-46. [http://dx.doi.org/10.1111/bjh.12107]

14. Heneghan C, Ward A, Perera R, et al. Self-monitoring of oral anticoagulation: Systematic review and meta-analysis of individual patient data. Lancet 2012;379(9813):322-334. [http://dx.doi.org/10.1016/ S0140-6736(11)61294-4]

15. Jaffer AK. Perioperative management of warfarin and antiplatelet therapy. Cleveland Clinic J Med 2009;76(Suppl 4):S37-S44. [http://dx.doi.org/10.3949/ccjm.76.s4.07]

16. Birnie DH, Healey JS, Wells GA, et al. Pacemaker of defibrillator surgery without interruption of anticoagulation. N Engl J Med 2013;368:2084-2093. [http://dx.doi.org/10.1056/NEJMoa 1302946]

17. Schulman S, Elbazi R, Zondag M, et al. Clinical factors influencing normalization of prothrombin time after stopping warfarin: A retrospective cohort study. Thromb J 2008;16:15. [http://dx.doi. org/10.1186/1477-9560-6-15]

18. Patel JP, Roberts LN, Arya R. Anticoagulating obese patients in the modern era. Br J Haematol 2011;155(2):137-149. [http://dx.doi.org/10.1111/j.1365-2141.2011.08826.x]

19. Baruch L. Laboratory monitoring of anticoagulant medications: Focus on the novel oral anticoagulants. Postgrad Med 2013;125(2):135-145. [http://dx.doi.org/10.3810/pgm.2013.03.2647]

20. Baron TH, Kamath PS, McBane RD. Management of antithrombotic therapy in patients undergoing invasive procedures. N Engl J Med 2013;368:2113-2124 [http://dx.doi.org/10.1056/NEJMra1206531]

21. Douketis JD, Spyropoulos AC, Spencer FA, et al. Perioperative management of antithrombotic therapy: Antithrombotic Therapy and Prevention of Thrombosis, 9th ed: American College of Chest Physicians Evidence-Based Clinical Practice Guidelines. Chest 2012;141(2 Suppl):e326S-e350S. [http://dx.doi. Evidence-Based Clinical Pro.1378/chest.11-2298]

22. Siegal S, Yudin J, Kaatz S, et al. Periprocedural heparin bridging in patients receiving Vitamin K antagonists: Systematic review and meta-analysis of bleeding and thromboembolic rates. Circulation 2012;126(13):1630-1639. [http://dx.doi.org/10.1161/CIRCULATIONAHA.112.105221]

23. David JS, Piriou V, Albaadejo P. Letter by David et al. regarding article, 'Periprocedural bleeding and thromboembolic events with dabigatran compared with warfarin: Results from the Randomized Evaluation of Long-term Anticoagulation Therapy (RE-LY) randomized trial. Circulation 2013;127:e504. [http://dx.doi.org/10.1161/CIRCULATIONAHA.112.133041]

24. Holbrook AM, Pereira JA, Labiris R, et al. Systematic overview of warfarin and its drug and food interactions. Arch Intern Med 2005;165(10):1095-1106. [http://dx.doi.org/10.1001/ archinte.165.10.1095

25. Halbritter K, Beyer-Westendorf J, Nowotny J, et al. Hospitalization for vitamin-K-antagonist-related bleeding: Treatment patterns and outcome. J Thromb Haemost 2013;11(4):651-659. [http://dx.doi. org/10.1111/ith. 12148]

26. Hohnloser SH, Hijazi Z, Thomas L, et al. Efficacy of apixaban when compared with warfarin in relation to renal function in patients with atrial fibrillation: Insights from the ARISTOTLE trial. Eur Heart J 2012;33(22):2821-2830. [http://dx.doi.org/10.1093/eurhearti/ehs274]

27. Kleinow ME, Garwood CL, Clemente CL, Whittaker P. Effect of chronic kidney disease on warfarin management in a pharmacist-managed anticoagulation clinic. J Manag Care Pharm 2011;17(7):523-530.

28. Hart RG, Pearce LA, Asinger RW, Herzog CA. Warfarin in atrial fibrillation patients with moderate chronic kidney disease. Clin J Am Soc Nephrol 2011;6(11):2599-2604. [http://dx.doi.org/10.2215/ CJN.02400311]

29. Hart RG, Eikelboom JW, Ingram AJ, Herzog CA. Anticoagulants in atrial fibrillation patients with chronic kidney disease. Nat Rev Nephrol 2012;8:569-578. [http://dx.doi.org/10.1038/nrneph.2012.160]

30. Sørensen R, Gislason G, Torp-Pedersen C, et al. Dabigatran use in Danish atrial fibrillation patients in 2011: A nationwide study. BMJ Open 2013;3:e002758. [http://dx.doi.org/10.1136/ bmjopen-2013-002758]

31. Patel MR, Hellkamp AS, Lokhnygina Y. Outcomes of discontinuing rivaroxaban compared with warfarin in patients with nonvalvular atrial fibrillation: Analysis from the ROCKET AF trial (Rivaroxaban Once-daily, Oral, Direct Factor Xa Inhibition Compared with Vitamin K Antagonism for Prevention of Stroke and Embolism Trial in Atrial Fibrillation). J Am Coll Cardiol 2013;61(6):651658. [http://dx.doi.org/10.1016/j.jacc.2012.09.057]

Accepted 16 September 2013 